\title{
CARACTERIZAÇÃO MICROBIOLÓGICA DO PROCESSO DE COMPOSTAGEM DE RESÍDUOS ORGÂNICOS EM PEQUENA ESCALA
}

Josemar Gonçalves de Oliveira Filho ${ }^{1}$, Carlito Pereira da Camara² ${ }^{2}$ Terezinha Cristina Farias de Sousa², Ítalo de Almeida $\mathrm{Cruz}^{2}$, Mariana Buranelo Egea ${ }^{1}$, Heloisa Alves de Sousa Falcão², Edilsa Rosa da Silva ${ }^{2}$

${ }^{1}$ Instituto Federal Goiano, Campus Rio Verde, GO. Instituto Federal de Brasília, Campus Planaltina, DF. E-mail: josemar.gooliver@gmail.com

\section{RESUMO}

Objetivou-se realizar a caracterização da microbiota responsável pela estabilização da matéria orgânica submetida ao processo de minicompostagem, além de relacionar a presença dos grupos e indicadores microbianos (bactérias, fungos e actinobactérias, coliformes totais e Escherichia coli) com a evolução do composto. A leira de compostagem foi montada e foram retiradas amostras nos tempos $0,9,17,24,31$ e 44 dias de compostagem para determinação da umidade, $\mathrm{pH}$ e quantificação de bactérias heterotróficas, actinobactérias, fungos totais, Coliformes Totais e E. coli. Foi possível detectar a presença dos indicadores Coliformes Totais e E.coli em todos os dias monitorados do processo de minicompostagem. Observou-se que a densidade das bactérias heterotróficas, no período de 45 dias do processo de minicompostagem, apresentou-se na faixa de $1,6 \times 10^{7} \mathrm{a}>3,0 \times 10^{7}$ unidades formadoras de colônias/grama (UFC. $\mathrm{g}^{-1}$ ) de composto. As actinobactérias apresentaram-se na faixa de $1,0 \times 10^{6}$ a $1,8 \times 10^{7}$ UFC. ${ }^{-1}$ de composto analisado e a contagem dos fungos totais apresentou-se na faixa de $10,0 \times 10^{6}$ a $8,3 \times 10^{7}$ UFC. $\mathrm{g}^{-1}$ de composto analisado. Concluiu-se que a densidade do grupo das bactérias heterotróficas, apesar de inicialmente estar abaixo dos fungos totais, se manteve superior a densidade das bactérias actinobactérias e fungos totais.

Palavras-chave: grupos microbianos; processo biológico; resíduos orgânicos.

\section{MICROBIOLOGICAL CHARACTERIZATION OF THE PROCESS OF ORGANIC WASTE COMPOSTATION ON A SMALL SCALE}

\begin{abstract}
The objective was to characterize the microbiota responsible for the stabilization of organic matter submitted to the minicompost process, and to correlate the presence of microbial groups and indicators (bacteria, fungi and actinobacteria, total coliforms and Escherichia coli) with evolution of the compound. It was possible to detect the presence of the bacteria of the Total Coliforms and E. coli indicators in all monitored days of the minicomposting process. The compost heater was assembled and samples were taken at $0,9,17,24,31$ and 44 days of composting to determine the humidity, $\mathrm{pH}$ and quantification of heterotrophic bacteria, actinobacteria, total fungi, total coliforms and E. coli. It was possible to detect the presence of Total Coliform and E.coli indicators on all monitored days of the mini-composting process. It was observed that the density of the heterotrophic bacteria, in the 45-day period of the minicomposting process, was in the range of $1.6 \times 10^{7}$ a $3.0 \times 10^{7}$ colony forming units/gram (CFU/g ${ }^{-1}$ ) of the compound. The actinobacteria were in the range $1.0 \times 10^{6}$ to $1.8 \times 10^{7} \mathrm{CFU} / \mathrm{g}^{-1}$ of compound tested and the total fungi count was in the range of $10.0 \times 10^{6}$ to $8.3 \times 10^{7} \mathrm{CFU} / \mathrm{g}^{-1}$ of compound analyzed. It was concluded that the density of the group of heterotrophic bacteria, although initially below total fungi, remained higher than the bacterial density of actinobacteria and total fungi.
\end{abstract}

Key words: microbial groups; biological process; organic waste. 


\section{INTRODUÇÃO}

A atividade humana caracteriza-se pela alta produção de resíduos orgânicos, tanto de origem domiciliar quanto de áreas rurais e urbanas, comerciais e industriais como refeitórios, padarias e açougues, entre outros. Esses resíduos geralmente são aterrados, incinerados ou descartados em terrenos baldios, e constituem-se não só em grande preocupação da sociedade, relacionada ao saneamento ambiental, como também em desperdício de nutrientes. Os resíduos orgânicos devem atender aos princípios sanitários e ecológicos para o seu tratamento de reduzindo assim os inúmeros impactos ambientais (HECK et al., 2013).

$O$ processo de compostagem pode ser definido como uma decomposição aeróbica e termofílica de resíduos orgânicos por populações microbianas heterotróficas existentes nos próprios resíduos, sob condições controladas, que produz um material parcialmente estabilizado de lenta decomposição, quando em condições favoráveis (INÁCIO; MILLER, 2009; PEIXOTO et al., 1989). Este processo auxilia no processamento de resíduos orgânicos de maneira adequada transformando-o em um fertilizante orgânico que quando utilizado oferece benefícios agronômicos, como redução da acidez potencial e aumento da disponibilidade de macronutrientes, além de representar um benefício de ordem social, devido ao descarte final menos impactante no meio ambiente (RODRIGUES et al., 2011).

Diversas comunidades microbianas predominam nas fases da compostagem. As bactérias, actinobactérias e fungos são responsáveis pela atividade microbiana que ocorrem durante o processo. Segundo Valente et al. (2009), o entendimento dos processos microbianos é importante para o reconhecimento da ciclagem de nutrientes e da dinâmica da matéria orgânica. Além disso, sabe-se que a intensidade da atividade dos microrganismos decompositores nos processos de compostagem está estritamente relacionada à diversificação e a concentração de nutrientes (PEREIRA NETO, 2007), sendo que a microbiota define a velocidade do processo, ao mesmo tempo que a temperatura (que é consequência do aumento do metabolismo microbiano envolvido no processo de biodegradação), a umidade, $\mathrm{o} \mathrm{pH}$, relação carbono/nitrogênio e presença de compostos tóxicos. A sucessão microbiológica, o envolvimento de comunidades microbiológicas e suas atividades, durante as fases específicas do processo de compostagem ainda são pouco conhecidas (FRANKE-WHITTLE et al., 2014).

Diante do acima exposto, o presente estudo teve por objetivo realizar a caracterização da microbiota responsável pela estabilização da matéria orgânica submetida ao processo de compostagem, além de relacionar a presença dos grupos microbianos (bactérias heterotróficas, fungos totais, actinobactérias, coliformes totais e E. coli) com a evolução do composto.

\section{MATERIAL E MÉTODOS}

Preparo e acompanhamento da leira de minicompostagem

Para a montagem da leira foram utilizados os seguintes resíduos orgânicos: esterco de ovino, restos de capina (capim seco), gravetos, terra, e lodo de esgoto proveniente de uma Estação de Tratamento de Esgoto (ETE) do Distrito Federal (DF, Brasil). A leira foi dimensionada em $1 \mathrm{~m}$ de diâmetro e $1 \mathrm{~m}$ de comprimento com o auxílio de trena, e depois fez-se a demarcação do piso com galhos de madeira com a construção de uma camada de galhos para propiciar a aeração da pilha. Em seguida, foi adicionada uma camada de $15 \mathrm{~cm}$ de capim seco alternando com uma camada de $8 \mathrm{~cm}$ esterco de ovino, até a pilha atingir 1 metro. $\mathrm{Na}$ penúltima camada foram adicionados 3 litros de lodo de esgoto e $6 \mathrm{~kg}$ de solo. Por fim, a leira foi coberta com capim seco conforme apresentado (Fig. 1).

Figura 1. Esquema de montagem da leira de compostagem. 


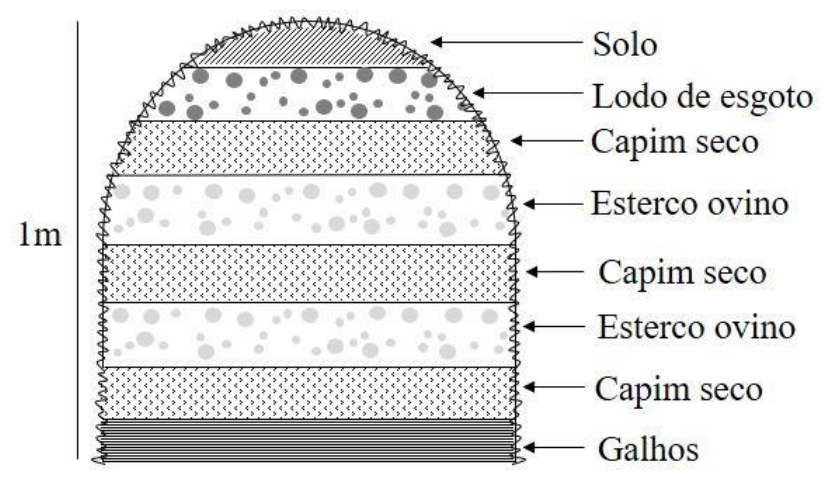

O revolvimento para aeração da leira foi realizado manualmente e a irrigação da pilha a cada 15 dias, ou quando necessário. 0 monitoramento das temperaturas foi realizado diariamente em três pontos distintos, estrategicamente escolhidos e para isso utilizouse termômetro de mercúrio com capacidade máxima até $100 \circ \mathrm{C}$. Foram retiradas três frações de amostras, sendo uma no centro na camada mediana nos tempos $0,9,17,24,31$ e 44 dias de compostagem que foram homogeneizadas com auxílio de tesoura e fracionadas para determinação da umidade, $\mathrm{pH}$ e quantificação de bactérias heterotróficas, actinobactérias, fungos totais, Coliformes Totais e E. coli.

\section{Determinações químicas e microbiológicas}

A determinação de $\mathrm{pH}$ foi realizada utilizando solução contendo 9 gramas da amostra em $60 \mathrm{~mL}$ de água destilada em 15 minutos diretamente em pHmetro de bancada.

Durante o estudo a verificação da umidade foi realizada pelo teste prático onde uma porção do composto é coletado com a mão e apertado. No entanto, como o teste não oferece precisão, realizou-se a determinação da umidade utilizano 20 gramas da amostra $\left(M_{i}\right)$ que foram incubados à $105{ }^{\circ} \mathrm{C}$ por 24 horas. Efetuou-se a pesagem $\left(\mathrm{M}_{\mathrm{f}}\right)$ e $\mathrm{O}$ cálculo realizado $\left(\mathrm{M}_{\mathrm{i}}{ }^{-}\right.$ $\left.M_{f} / M_{f}\right) \times 100$ e o resultado expresso em percentual.

A determinação de bactérias heterotróficas, actinobactérias, fungos totais, Coliformes Totais e $E$. coli foi realizada segundo as recomendações de Silva et al. (2007) e American Public Health Association (2000) com adaptações. 10 gramas da amostra foram homogeneizadas em $90 \mathrm{~mL}$ de solução salina $(0,9 \% \mathrm{NaCl})$ (diluição $1: 10)$ e a partir desta diluição, preparou-se as diluições 1:100, 1:1000 e 1:10.000, e uma alíquota de $0,1 \mathrm{~mL}$ da última diluição foi espalhada no centro das placas contendo o meio de cultura selecionado (técnica Spread Plate). Para as bactérias heterotróficas foi utilizado o meio Agar PCA (Plate Count Agar), para as bactérias actinobactérias o meio Agar amido caseína e para os fungos totais o meio Agar PDA (Agar Batata Dextrose). Incubou-se em estufa microbiana à $35^{\circ} \mathrm{C}$ por até 48 horas (Ágar PCA) e à $30^{\circ} \mathrm{C}$ (Ágar PDA), por 72 horas e então efetuou-se a contagem das colônias de microrganismos.

Para a determinação da presença de Coliformes totais e $E$. coli, utilizou-se o método cromogênico, que verifica a capacidade do microrganismo de metabolizar determinado substância (ONPG, orto-nitrofenilgalactopiranosídeo e MUG, methyl-umbelipherilglucuronide) provocando alteração de cor (Coliformes Totais) e emissão de fluorescência sob luz ultra-violeta (UV) (E. coli). Efetuou-se a inoculação do reagente cromogênico na diluição previamente preparada 1:1000 (1 frasconete com reagente para $100 \mathrm{~mL}$ de amostra diluída em frascos especiais que não emitem fluorescência sob UV). A incubação dos frascos inoculados foi em estufa microbiana à $35^{\circ} \mathrm{C}$ por até 48 horas (Ágar PCA) e então efetuou-se a leitura dos resultados (mudança de cor da amostra e emissão de fluorescência sob luz UV em câmara escura).

\section{Análises estatísticas}

Os resultados quando necessário foram submetidos à análise de regressão e as equações ajustadas aos modelos de dois fatores máximos dependentes.

\section{RESULTADOS E DISCUSSÃO}

$A$ determinação da umidade durante $O$ processo de minicompostagem (Fig. 2A) apresentou-se na faixa de $37 \%$ a $51 \%$ com o ajuste de equação de $80 \%$. A verificação prática manual mostrou umidade adequada durante o processo de compostagem, no entanto, os 
resultados do teor de umidade apontaram valores abaixo de níveis seguros (entre 37\%-39\%). De acordo com Inácio e Miller (2009), os teores de umidade devem ficar em torno de $40 \%$ e $65 \%$, mas essa faixa pode variar conforme a aplicação, como por exemplo, na produção de cogumelos, em que teor de umidade deve ser entre $68 \%$ $74 \%$. Valores entre $40 \%$ e $65 \%$ foram relatados por Sivakumar et al. (2007) em compostagem de carcaças de frangos por estimular a atividade microbiana.

A umidade é um fator importância para o processo de compostagem, pois quando esta deficiente ou em excesso pode afetar a atividade microbiana na leira. Concentrações abaixo de $30 \%$ reduzem consideravelmente a atividade microbiana, aumentando o período do processo e valores maiores que $60 \%$ bloqueiam a porosidade da leira, causando anaerobiose (diminuição do oxigênio na leira) e levando ao processo de fermentação (PEREIRA NETO; LELIS, 1999; RODRIGUES et al., 2006).

A temperatura, entre outros é um fator bastante importante que afeta 0 desenvolvimento dos micro-organismos, onde cada um deles apresenta uma faixa adequada para o crescimento, e, por ela, realiza-se a classificação: psicrófilos $\left(15^{\circ}\right.$ a $\left.20^{\circ} \mathrm{C}\right)$, mesófilos $\left(25^{\circ}\right.$ a $\left.40^{\circ} \mathrm{C}\right)$ e termófilos $\left(50^{\circ}\right.$ a $\left.60^{\circ} \mathrm{C}\right)$ (BLACK, 2002).

O monitoramento da temperatura durante o processo de minicompostagem (Fig. 2B) apresentou-se na faixa de $23-52^{\circ} \mathrm{C}$, sendo que a temperatura mais baixa foi verificada no tempo zero e a mais alta no décimo dia. Na maioria dos dias a temperatura $\left(26^{\circ}\right.$ a $\left.40^{\circ} \mathrm{C}\right)$ mostrou-se adequada para os microrganismos mesófilos (temperatura ótima até $45^{\circ} \mathrm{C}$ ), semelhante ao relatado por Maragano et al. (2007). A temperatura aumenta em decorrência do aumento do metabolismo microbiano no processo de degradação. Considerando a sucessão de comunidades microbianas no sistema de compostagem, o processo continua normalmente durante a fase termofílica.

Figura 2. Monitoramento da umidade (\%, Fig. 2A) e temperatura (으, Fig. 2B) da leira de minicompostagem no período de 45 dias.

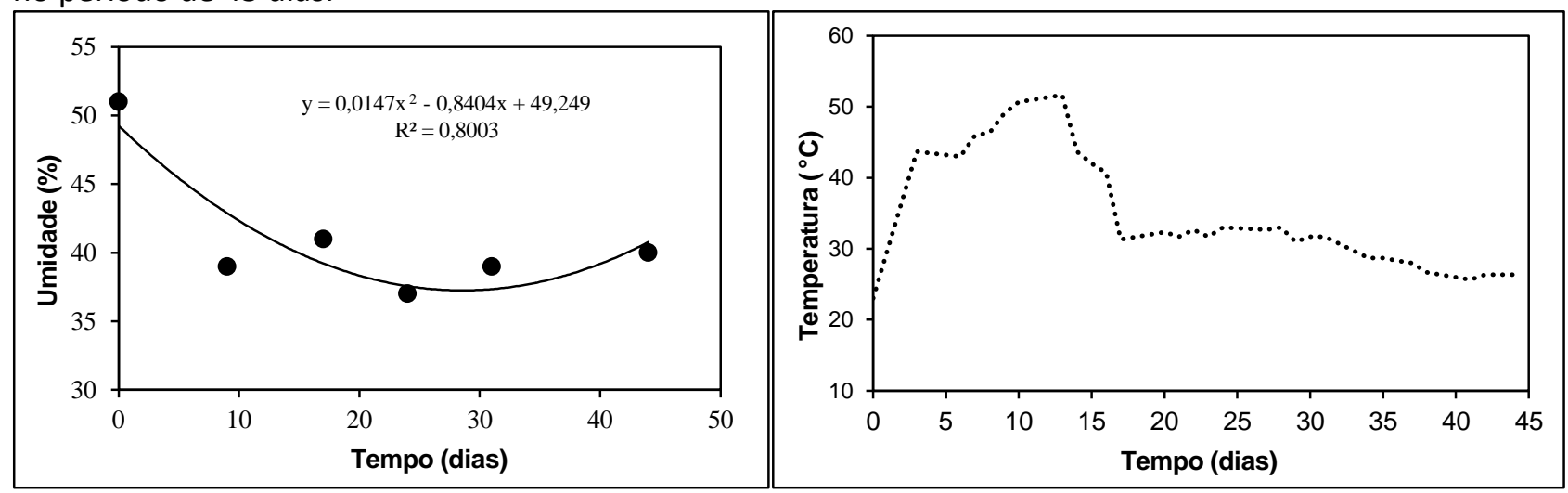

No presente estudo, foi possível verificar que a faixa de temperaturas favorável a atuação dos microrganismos termófilos foi curta (próximo de $60^{\circ} \mathrm{C}$ ). A menor temperatura da composteira observada neste estudo pode ter ocorrido em função de uma redução da umidade e/ou de uma menor concentração de nutrientes no substrato e/ou, ainda, devido a um menor tamanho da leira, o que segundo Pereira Neto (2007), proporciona uma maior perda de calor para o ambiente.

Segundo Inácio e Miller (2009), o processo de compostagem envolve três faixas de temperatura: a i) termófila, que apresenta temperaturas situadas entre $50-55^{\circ} \mathrm{C}$ e máximo de $85^{\circ} \mathrm{C}$; ii) mesófila, onde as temperaturas vão de $25-40^{\circ} \mathrm{C}$, podendo chegar ao máximo de $43^{\circ} \mathrm{C}$ e; iii) criófila (crio=frio) quando a temperatura da composteira atinge a temperatura ambiente, coincidindo com a fase de maturação do composto.

A minicomposteira iniciou a sua fase termofílica no oitavo dia e permaneceu até o décimo terceiro, contabilizando cinco dias nesta fase (Fig. 2B). Após isto, iniciou-se a fase mesófila, que permaneceu até o trigésimo quinto dia, contabilizando 20 dias. A fase de maturação do composto iniciou-se a partir do 36ㅇ e 
permaneceu até o 45‥ Neste período, a temperatura da leira coincidiu com a temperatura ambiente e permaneceu até o final do processo. $\mathrm{O}$ curto período de fase termofílica $\left(<65{ }^{\circ} \mathrm{C}\right)$ pode ter sido insuficiente para promover a sanitização do material.

$\mathrm{O}$ monitoramento do $\mathrm{pH}$ durante $\mathrm{O}$ processo de minicompostagem (Fig. 3A) apresentou-se em média na faixa de 7,5 a 8,9 , e o $\mathrm{pH}$ mais baixo foi verificado no tempo zero e a mais alta no 170 e 240 dias de medição, com o ajuste de equação de $78 \%$.

Figura 3. Monitoramento do $\mathrm{pH}$ (Fig. $3 \mathrm{~A}$ ) e da contagem de bactérias heterotróficas, actinobactérias e fungos totais (Fig. 3B) da leira de minicompostagem no período de 45 dias.

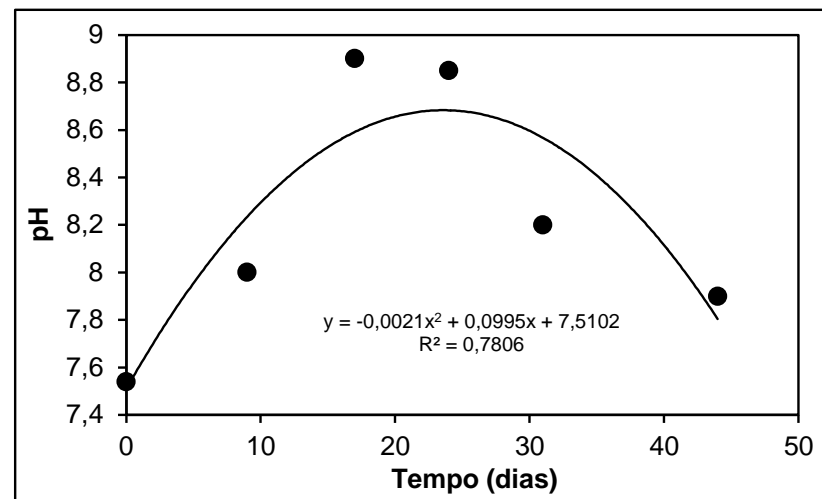

Zhang e He (2006), estudando a compostagem de dejetos sólidos de suínos misturados com serragem demonstraram que inicialmente, encontrou $\mathrm{pH}$ levemente ácido que ao longo do processo tornou-se alcalino, e por fim, novamente ácido, porém em valores próximos da neutralidade, sendo um importante indicativo de estabilização da biomassa. O mesmo ocorreu no trabalho de Jahnel et al. (2008) estudando a compostagem de resíduos urbanos observou que no início do processo a massa em compostagem apresentou-se ácida $(\mathrm{pH}$ em torno de 5,0 ) e, após cerca de 50 dias, atingiu valores próximos a 8,5 .

Os valores de $\mathrm{pHs}$ observados ao longo do experimento estão próximos da faixa considerada ótima para o desenvolvimento dos microrganismos responsáveis pela compostagem (entre 5,5 e 8,5) (RODRIGUES et al., 2006). Porém, Pereira Neto (2007) afirma que a compostagem pode ser desenvolvida em uma

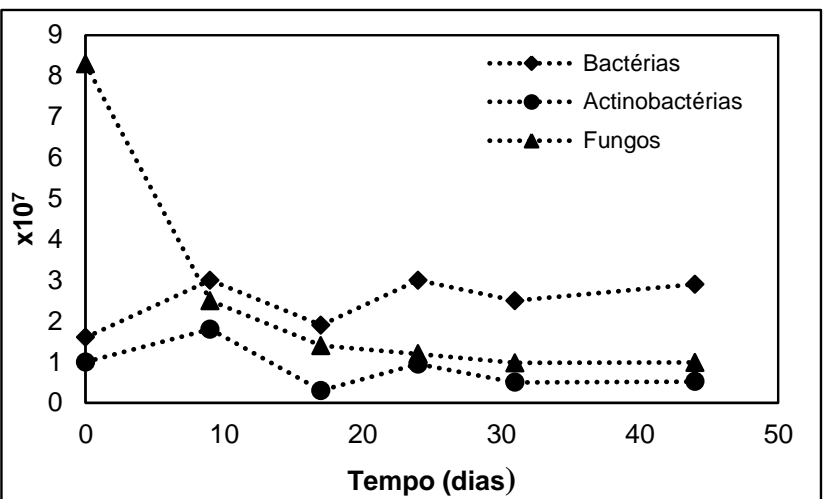

faixa de $\mathrm{pH}$ entre 4,5 e 9,5, sendo que os valores extremos são automaticamente regulados pelos microrganismos.

Inácio e Miller (2009), registraram que no início da decomposição orgânica o meio da compostagem se torna ácido pela liberação de ácidos orgânicos, mas, em seguida, há formação de ácidos húmicos que também formam humatos alcalinos. $\mathrm{O} \mathrm{pH}$ sofre ainda efeito da mineralização do nitrogênio orgânico, que corresponde a maior parte do nitrogênio da matéria orgânica transformado em nitrogênio amídico e depois em nitrogênio amoniacal, elevando assim o pH devido à reação alcalina, característica da amônia.

A atividade biológica em uma leira de compostagem é complexa e dependente de fatores e relações ecológicas, isto é, da relação entre as populações de microrganismos, (constituídos por diversas espécies de bactérias, actinobactérias e fungos) e destas com os fatores 
do ambiente da leira, os quais sofrem influência também do sistema de manejo. Além disso, as transformações químicas e físicas, que são realizadas pela atividade microbiana, são diretamente dependentes das características físico-químicas da mistura dos substratos utilizados no processo (VALENTE et al., 2009).

Uma comparação dos valores determinados das bactérias heterotróficas, actinobactérias e fungos totais é apresentada na Fig. 3B. É possível observar que a densidade do grupo das bactérias heterotróficas, apesar de inicialmente estar abaixo dos fungos totais, se manteve superior a densidade das actinobactérias e fungos totais.

A quantificação das bactérias heterotróficas, também denominadas de mesófilos aeróbios (Fig. 3B), no período de 45 dias, apresentou-se na faixa de $1,6 \times 10^{7} \mathrm{a}>3,0 \mathrm{x}$ $10^{7}$ unidades formadoras de colônias/grama (UFC. $\mathrm{g}^{-1}$ ) de composto analisado. Os microrganismos mesófilos são dominantes na compostagem na fase inicial, quando as temperaturas são relativamente baixas. Acima de $45^{\circ} \mathrm{C}$, os mesófilos podem morrer ou tornar-se dormentes, mas, quando a temperatura decrescer eles voltam a recolonizar a biomassa da compostagem.

A determinação dos actinobactérias, também denominadas actinobactérias ou bactérias filamentosas (Fig. 3B) no presente estudo, no período de 45 dias, apresentou-se na faixa de $1,0 \times 10^{6}$ a $1,8 \times 10^{7}$ UFC. $g^{-1}$ de composto analisado. Actinobactérias são uma importante parte da comunidade microbiana aeróbia na compostagem por atuarem na conversão da lignina, hemicelulose e celulose. A maior contagem de actinobactérias $\left(1,8 \times 10^{7}\right)$ foi observada no 9o dia de compostagem, coincidindo com o aumento da temperatura de leira (Fig. 2B). $\mathrm{Na}$ compostagem, os actinobactérias se destacam na fase termofílica $\left(>40^{\circ} \mathrm{C}\right)$. Alguns gêneros de actinobactérias são termófilos, tolerando a temperaturas próximas de $50^{\circ} \mathrm{C}-60^{\circ} \mathrm{C}$ (TUOMELA et al., 2000). No presente trabalho, o monitoramento das actinobactérias foi realizado à temperatura de $30^{\circ} \mathrm{C}$, o que não favoreceu $O$ isolamento de actinobactérias termófilas, além do fato do processo de minicompostagem ter registrado em sua maior parte temperaturas na faixa de $26^{\circ}$ a $40^{\circ} \mathrm{C}$, consideradas mesófilas.

A quantificação de fungos totais (fungos filamentosos e leveduras) (Fig. 3B), apresentou-se na faixa de $10,0 \times 10^{6}$ a $8,3 \times 10^{7}$ UFC.g ${ }^{-1}$ de composto analisado. Embora inicialmente a densidade do grupo de fungos apresentou-se relativamente alta, no 9o dia houve um decréscimo, que coincidiu com o aumento da temperatura da leira (Fig. 2A) e início da fase termofílica. No processo de compostagem, os fungos são praticamente excluídos da fase de alta temperatura, pois apenas uma pequena parcela do grupo fúngico pode crescer acima de $50^{\circ} \mathrm{C}$ (INÁCIO; MILLER, 2009).

No presente trabalho, foi observado que a densidade fúngica apresentou-se estável com redução a partir do 31 ㅇ dia e 44 ㅇ dias avaliados.

Em todo o processo de compostagem foi detectado a presença das bactérias do grupo Coliformes Totais e E.coli. O esterco de ovinos e lodo de esgoto, utilizados no processo de compostagem, são fontes de bactérias do grupo coliforme e E.coli, devido aos altos índices de contaminação destes materiais. Este resultado foi esperado principalmente por que não foi atingido temperaturas $>65 \circ \mathrm{C}$, necessárias para o eficaz controle ou eliminação de patógenos em processos de compostagem utilizando materiais com potencial de contaminação. Em termos biológicos, os limites de operação da temperatura podem ser classificados como: $>55 \mathrm{C}$ para a maximização da sanitização; 45-55C para a maximização da taxa de biodegradação e entre 35 - 45ㅇ C para maximizar a diversidade microbiana (INÁCIO; MILLER, 2009)).

\section{CONCLUSÕES}

O processo de compostagem estudado mostrou o teor de umidade entre 37 a 51\%, temperatura entre $23^{\circ}$ a $52^{\circ} \mathrm{C}$ e pH entre 7,5 a 8,9 durante os 45 dias. A densidade do grupo das bactérias heterotróficas, apesar de inicialmente estar abaixo dos fungos totais, se manteve superior a densidade das bactérias actinobactérias e fungos totais. Ainda, observouse que a qualidade microbiológica do produto final da compostagem é dependente dos substratos utilizados já que foi possível detectar a presença das bactérias do grupo Coliformes Totais e E.coli em todos os dias monitorados do processo de minicompostagem.

\section{REFERÊNCIAS}

AMERICAN PUBLIC HEALTH ASSOCIATION. Standard Methods for the Examination of Water and Wasterwater. 20. ed. Washington, D.C.: American Public Health Association, 2000. 
BLACK, J.G. Microbiologia: fundamentos e perspectivas. Rio de Janeiro: Guanabara Koogan, 2002, 829p.

FRANKE-WHITTLE, I. H.; CONFALONIERI, A.; INSAM, H.; SCHLEGELMILCH, M.; KÖRNER, I. Changes in the microbial communities during cocomposting of digestates. Waste Management, v. 34, n.3, p. 632-641, 2014. https://doi.org/10.1016/j.wasman.2013.12.009

HECK, K.; MARCO, E.G.; HAHN, A.B.B.; KLUGE, M.; SPILKI, F.R.; DAND, S.T.V.D. Temperatura de degradação de resíduos em processo de compostagem e qualidade microbiológica do composto final. Revista Brasileira de Engenharia Agrícola e Ambiental, v.17, n.7, 2013. https://doi.org/10.1590/S1415-

$\underline{43662013000100008}$

INÁCIO, C.T.; MILLER, P, R. M. Compostagem: ciência e prática para a gestão de resíduos orgânicos. Rio de Janeiro: Embrapa Solos, 2009. $156 \mathrm{p}$.

JAHNEL, M.C.; MELLONI, R.; CARDOSO, E.J.B.N. Maturidade de composto de lixo urbano. Scientia Agricola, v.56, n.2, p.301-304, 2008. https://doi.org/10.1590/s0103-

$\underline{90161999000200007}$

KIEHL, E.J. Manual de compostagem: maturação e qualidade do composto. 3. ed. Piracicaba, 2002, $171 p$.

PEIXOTO, R.T.G. Compostagem: opção para o manejo orgânico do solo. Londrina. IAPAR: 1988. 48p. (IAPAR. Circular, 57).

PEREIRA NETO, J.T. Manual de compostagem: processo de baixo custo. Viçosa: UFV, 2007. $81 \mathrm{p}$

PEREIRA NETO, J.T.; LELIS, M.P.N. Importância da umidade na compostagem: uma contribuição ao estado da arte. In: CONGRESSO BRASILEIRO DE ENGENHARIA SANITÁRIA E AMBIENTAL, 20. Anais... Rio de janeiro: ABES, 1999. p. 1691-1698.

RODRIGUES, M.S.; SILVA, F.C.; BARREIRA, L.P.; KOVACS, A. Compostagem: reciclagem de resíduos sólidos orgânicos. In: SPADOTTO, C.A.; RIBEIRO, W. Gestão de resíduos na agricultura e agroindústria. Botucatu: FEPAF, 2006. p.63-94. https://doi.org/10.1590/S1415-

\section{$\underline{43662011000800004}$}

RODRIGUES, P.N.; ROLIM, P.M.; NETO, E.B.; COSTA, R.N.T.; PEDROSA, E.M.R. Efeito do composto orgânico e compactação do solo no milho e nutrientes do solo. Revista Brasileira de Engenharia Agrícola e Ambiental, v.15, p.788793, 2011. https://doi.org/10.1590/S1415$\underline{43662011000800004}$

SILVA, N.; JUNQUEIRA, V. C.A.; SILVEIRA, N. F.A.; TANIWAKI, M.H.; SANTOS, R.F.S.; GOMES, R.A.G. Manual de métodos de análise microbiológica de alimentos. 3. ed. São Paulo: Livraria Varela, 2007, 536p.

SIVAKUMAR, K.; KUMAR, V.R.S.; JAGATHEESAN, P.N.R.; VISWANATHAN K.; CHANDRASEKARAN, D. Seasonalvariations in compostingprocess of deadpoultrybird. Bioresource Technology, v.99, n.9, p.3708-3713, 2008. https://doi.org/10.1016/j.biortech.2007.07.023

TUOMELA, M.; VIKMAN, M.; HATAKKA, A.; ITAVAARA, M. Biodegradation of lignin in a compost environment: a review. Bioresource Technology, v.72, p.169-183, 2000. https://doi.org/10.1016/S0960-8524(99)00104-2

VALENTE, B. S.; XAVIER, E.G.; MORSELLI, T.B.G.A.; JAHNKE, D.S.; BRUM Jr, B.S.; CABRERA, B.R.; MORAES, P.O.; LOPES, D.C.N. Fatores que afetam o desenvolvimento da compostagem de resíduos orgânicos. Arquivos de Zootecnia, v.69, p. 1-3, 2009.

ZHANG, Y.; HE, Y. Co-compostig solids wine manure with pine sawdust as organic substrate. Bioresource Technology, v.97, n.5, p. 2024-2031, 2006.

https://doi.org/10.1016/j.biortech.2005.10.004

Recebido para publicação em 29/08/2017

Revisado em 20/11/2017

Aceito em 22/01/2017 